Finally, there is the problem of information. The data flow will continue to increase and the various data centers will become more important. The question of having active or passive centers must be given serious thoughts; there were divided views on this at Symposium No. 50. Many astronomers may feel that printed catalogues available in the observatory library are more useful - just because they are on the spot when needed - than data on magnetic tape at a remote data center. However, the evolution in computer technology is fast and a situation in favour of the passive centers may soon exist. In the meantime it appears important that catalogues and supplements to existing catalogues be printed and distributed as widely as possible. Among the larger data banks not yet generally available is Bibelman's bibliography of spectroscopic data; it would be welcome to see it at least in a punch card format.

B. E. WESTERLUND

President of the Commission

\title{
WORKING GROUP FOR COLLECTION OF PHOTOMETRIC AND SPECTROSCOPIC DATA
}

This Group was formed during the meeting of the General Assembly in Brighton on August 22, 1970 with the following members: B. E. Westerlund, W. P. Bidelman, M. Barbier and B. Hauck. In the beginning of $1972 \mathrm{C}$. O. Jaschek was asked to join this group as he is also a member of the IAU Working Group on Numerical Data.

The first work of our Group was to establish a list of catalogues recently published or in preparation. For this purpose a circular letter was sent to all members of our Commission. Dr Crawford, President of Commission 25, kindly sent our letter to the members of his Commission. The first list was published in the "Bulletin d'Information no. 1 du Centre de Données Stellaires de Strasbourg". A complement has been published in the second issue of this bulletin. We thank all colleagues who have contributed, and we hope that many colleagues will contribute to the success of a second list sending us their information and data.

At the IAU Symposium no. 50 we decided to send a questionnaire to all members in order to help us with the selection of spectroscopic and photometric catalogues, which should be punched or registered on magnetic tape. 10 answers were received. Then the "Centre de Données Stellaires" was asked to punch those lists that were not yet on machine readable form.

All information concerning the material collected by our Group and available has been published in the "Bulletin d'Information du Centre de Données Stellaires".

The list of photometric catalogues compiled by B. Hauck and available at Strasbourg is given below.

In the future our Group should devote more effort to the collection of spectroscopic data. It would be most helpful, if contributors send information and data to $\mathrm{Dr} C$. O. Jaschek and $\mathrm{Dr}$ W. P. Bidelman.

B. HAUCK

Chairman of the Working Group

List of photometric catalogues available at Strasbourg

(1) uvby system.

(2) two-micron sky survey (Cal Tech).

(3) six-color system; (a) Nicollier catalogue, (b) Kron catalogue.

(4) Catalogue of Blanco et al. $(U B V)$.

(5) A new catalogue of Stellar $U B V$ photoelectric photometry (see the description of Mermilliod in the "Bulletin no. 3 du Centre de Données Stellaires de Strasbourg").

(6) Tape with measurements in the following systems: Borgman, Argue, Kruszewski, Vilnius, $(P, V),(U B V r)_{20}$, Walraven, DDC, DAC, Bahng, Wood, Willstrop.

(7) Geneva system.

In order to obtain a tape write to Dr J. Jung, Director, Centre de Données Stellaires, Observatoire de Strasbourg, 11, rue de l'Université, F-67 Strasbourg. 